\title{
QUANTIFICATION OF IMPACTS ON THE TRANSPORT SERVICEABILITY AT THE LOSS OF FUNCTIONALITY OF SIGNIFICANT ROAD INFRASTURUCTURE OBJECTS
}

Incidents and unexpected phenomena occurrence in transport significantly affect the performance and capacity parameters of traffic infrastructure and its important objects. The objective of this article is to indicate possible uses of software tools to model the traffic at the loss of functionality of potential elements of critical road infrastructure and to demonstrate the possibility of their efficient use. The conducted case study applied the simulation models for quantification of the infrastructure traffic load under standard conditions as well as during the constraint of the transport system operation, i.e. after implementation of restrictive conditions (e.g. considering shutdown of an important bridge). The solution of the situation at the shutdown of an important element of infrastructure is possible to be designed, verified and modified using appropriately devised adequate virtual models. By this means, it is possible to predict the significance of the shutdown - criticality and influence of the loss of the functionality considering the transport serviceability parameters of the road infrastructure in the affected area.

Keywords: Critical road infrastructure, loss of function, traffic modelling, traffic flow, transport serviceability, incident.

\section{Introduction}

In Slovakia, the problem of complex risk management in the field of critical traffic infrastructure is quite new. In addition to the specific legislative framework [1], which defines the basic terminology and the necessary information base focused on the sectors and sub-sectors of critical infrastructure (CI), there is no singular methodological approach designed for objective identification of the elements of so-called critical infrastructures in defined areas so-called sectors. We notably absent the complex methodology, which would enable the conduction of the risk analyses and quantification of the impacts associated with the loss of functionality of important elements of traffic infrastructure, considered as "potentially critical".

Within the transport sector, in the field of threat identification and risk assessment of the potential elements of critical infrastructure, there is a methodology developed, which integrates main phases of the risk management of potential objects of $\mathrm{CI}$ in the road and rail transport.

The purpose of this methodology is to define the set of typological markers, criteria, approaches and methods suitable for implementation of the process of CI elements identification to the design of efficient systems of security measures, reducing the probability of the loss of infrastructure functionality to an acceptable level. The methodological approach generally comprises of three basic areas according to Fig. 1.

Phase 1: Identification of the species and types of traffic infrastructure objects, destruction of which would have a significant negative impact on the assurance of basic functions of the transport system.

Phase 2: Defining the most probable threats leading to the dysfunction of the potential objects of the road traffic

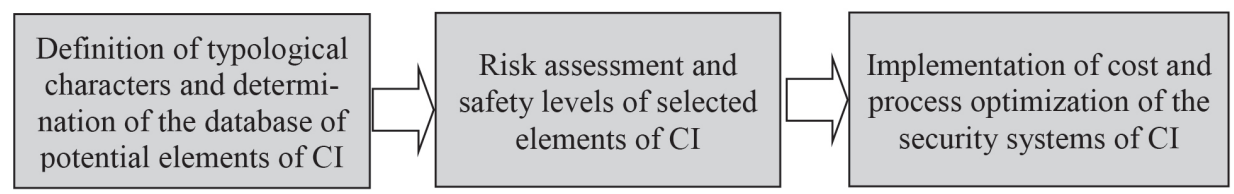

Fig. 1 Basic phases of applied methodology [authors]

\footnotetext{
* ${ }^{1}$ Bohus Leitner, ${ }^{1}$ Maria Luskova, ${ }^{2}$ Alan O'Connor, ${ }^{3}$ Pieter van Gelder

${ }^{1}$ Faculty of Security Engineering, University of Zilina, Slovakia

${ }^{2}$ Department of Civil, Structural \& Environmental Engineering, Trinity College Dublin, Ireland

${ }^{3}$ Safety and Security Science section, Delft University of Technology, The Netherlands

E-mail: Bohus.Leitner@fbi.uniza.sk
} 
infrastructure [2], prediction of the risk exposure [3] and the assessment of the possibilities to minimize the threats of individual types of infrastructure objects [4].

Phase 3: Estimation of the time for recovery of the CI objects due to the loss of their functionality [5], assessment of their temporary replacement, alternatively their detour using traffic modelling [6]. An important task is to optimize the protection of important subject using existing traffic management systems, intelligent traffic systems [2] as well as new ways of object protection in order to reduce the impacts of the loss of functionality of a traffic system element.

The article presents the most important results of the conducted case study. Its objective is to demonstrate the possibilities and efficiency of using traffic flow modelling when assessing the importance of the road infrastructure object and quantification of the influence of the object's functionality loss on the traffic load of a part of road infrastructure. For comparison, we tracked the capacity and performance parameters of the road infrastructure under standard conditions and particularly in the situation when the operation of the traffic system is limited, i.e. after the introduction of restrictive conditions (e.g. shutdown of a bridge)

\section{Traffic modelling and tools for analysis of the traffic flow models}

Modelling traffic by the means of appropriate software represents an efficient method in the field of transport engineering. Their use not only involves the simulation of the traffic control itself, but it represents a set of tools from simple single-purpose application to complex systems for implementation of intricate analyses of the traffic networks and processes. Simulation models of the traffic flow were created as a tool for theoretical recognition of the influence of various factors on the analysed values of the basic traffic characteristics as well as for on-line identification of some parameters such as capacity of the flow movement in various conditions, investigation of the influence of an accident on the traffic flow behaviour, quantification of the length of column before the restriction of the network etc. [6].

Currently, specialized software products are being used for traffic problem solutions (e.g. Getram/Aimsun, PTV Vissim, OmniTrans and many others). These tools have vast possibilities of simulations, settings and other useful functions and, in a relatively short time, it is possible to simulate numerous scenarios of a traffic situation and run calculation of efficiency parameters of certain sections or individual objects of the traffic infrastructure. Using simulations makes it possible to model actual and prospective state of the traffic in selected traffic mode, as well as state of operational load of selected sections and elements of the road network. The mentioned software most frequently uses either microscopic dynamic simulation of the traffic which simulates behaviour of an individual vehicle in the flow or macroscopic principle which characterizes the traffic flow globally by the means of selected characteristics [7].

In the realization phase of the case study, the simulation tool OmniTrans [8] was used. This software tool is designed for macroscopic modelling of medium sized and large networks and involves all modes of the road traffic, i.e. so-called multimodal modelling tool. The software is suitable for prediction and solution of a traffic congestion and its impacts on the roads linking neighbouring agglomerations or impacts on individual areas - so-called traffic districts. Dynamic models enable us to create congestions in virtual environment in selected timescales and during modelling of several variants, they allow their cross comparison and assessment of solutions [9].

\section{Impacts on the transport serviceability in adjacent areas due to the functionality loss of an important object of the road network}

The form of the case study was selected to demonstrate efficiency of the use of software tools for traffic modelling when assessing the criticality of road infrastructure objects and expressing the impacts of their potential failure. The study was based on the assumption of the occurrence of a negative phenomenon and its influence on transport services and resulting changes in the capacity of the monitored road network sections. The first task solved was a model representing the normal operating conditions - traffic infrastructure without restrictions. The second tasks deals with a temporary restriction of the transit over a bridge and resulting traffic situation. The last problem analysed is a case of long-term breakdown of the bridge with defining the alternative proposal of redirection of the vehicle flow to a traffic detour.

\subsection{Problem formulation, description of the object and chosen location}

Within the traffic system, various unexpected phenomena can occur due to the change of climate conditions and human activities such as increasing number of vehicles in the road traffic. Their consequences are mostly traffic congestion and resulting speed limitation of the traffic flow, partial or complete obstruction of the area etc. The objective of the case study is to demonstrate the benefits of the use of software support for quantification of the traffic flow parameters during solution of partial or complete restriction of the traffic at certain spot of infrastructure, e.g. bridge, road junction or tunnel. 


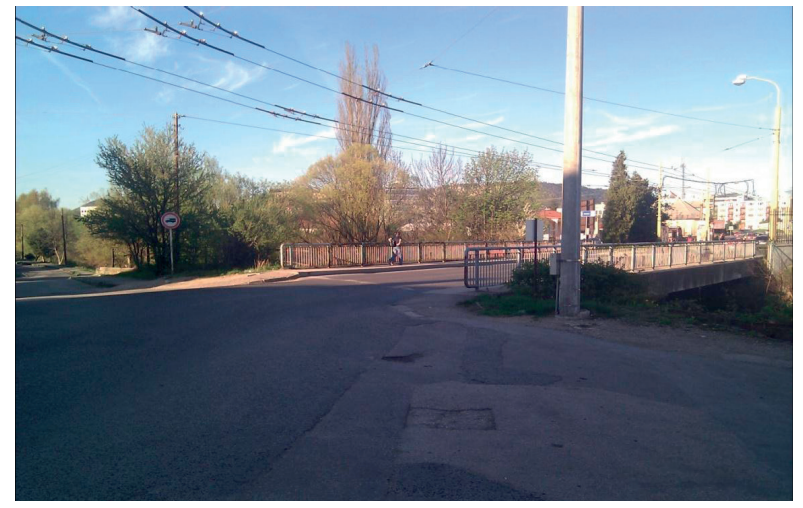

Fig. 2 Chosen bridge [authors]

Sub-objectives of the case study:

- Calculation of the road network load at the selected location in the normal state (working day, morning peak, times: 7:05, 8:30 and 8:55 am).

- Prediction of the traffic load at the occurrence of a restriction on the selected object (bridge structure according to Fig. 2).

- Design of the optimal variant of detour and prediction of the traffic load after the implementation of the measures so that the traffic would flow smoothly.

Expected outcome of the study is confirmation or negation of the assumption that during the restriction of the traffic flow (e.g. due to decrease in transitivity of the selected object), after the implementation of the designed alternative solution, the adjacent roads will be able to serve required traffic demand in the area.

The selected road section ( $3^{\text {rd }}$ class road III/5181 with the length of $1.25 \mathrm{~km}$ - beginning of the section is on Rondel, the end of the section is the intersection to Horky) is a main connection between the town centre of Zilina and residential district Hajik, suburb Banova and neighbouring villages Horky, Brezany, Bitarova and Ovciarsko.

As the important infrastructure object in this area we selected the bridge which allows vehicles to pass over the river Rajcianka. The reason to choose this object was the flood in 2010 on the river Rajcianka in the suburb Zilina - Zavodie when after long rains a flood activity of $3^{\text {rd }}$ degree was declared (serious consideration was given to the restriction of the traffic on this object). In the selected area, there is one circular and 8 level intersections.

\subsection{Input data and data collection}

The data necessary to define the traffic matrix were obtained from the traffic survey. The traffic survey was conducted at the time from 7:00 to 9:20 am (11th April 2014, Friday - as a critical day of the week), on the streets Horecka and Osloboditelov. The total sum of vehicles includes personal cars, lorries and public transport vehicles too. For illustration, the results of the survey on Horecka Street are provided in Fig. 3.

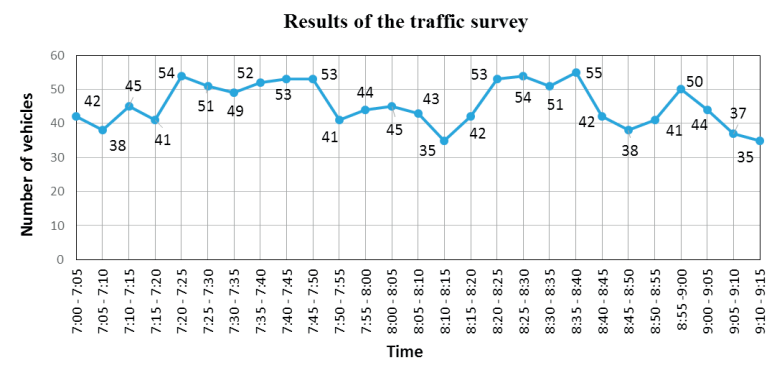

Fig. 3 The results of the traffic survey [authors]

In case there is no time to conduct the traffic survey, e.g. due to unexpected emergency situation, it is possible to obtain approximate information about the traffic flow from an older database. It is mainly the statistic data from the national census of traffic on the road network in Slovakia. The last traffic census monitoring the extend of the use of motorways, expressways, roads of $1^{\text {st }}$ and $2^{\text {nd }}$ class and some road sections of the $3^{\text {rd }}$ class were conducted in 2010 .

\subsection{Preparation of the simulation model}

\section{Step 1. Inserting maps, plotting zones and defining districts}

For more accurate plotting of the traffic network, it is useful to have a base map which would serve for drawing the transport network. As a base map, we used the map of the selected area from the portal Google maps. After inserting the base map, particular zones representing individual town districts were plotted in. After drawing the zones, we defined the so-called sectors, out of which the traffic flows will be directed. In total, 8 sectors were defined in the model (Fig. 4).

Step 2. Plotting traffic hubs, road network and defining intersections

After defining the zones and sectors, it was necessary to set so-called traffic hubs in order to create supporting traffic network. The traffic hub is usually placed on the base map at the road intersection. After defining the traffic hubs, it is necessary to define road sections between them which are usually named according to the actual street names.

When designing the road network and defining the performance and capacity parameters for particular road sections, we used the standard STN 636110 Designing local roads [10]. Equation for calculating the limit values of the traffic flow intensities is given as

$\mathrm{l}_{\mathrm{p}}=\mathrm{l}_{\mathrm{z}} \times \mathrm{k}_{\mathrm{k}} \times \mathrm{k}_{\mathrm{s}} \times \mathrm{k}_{\mathrm{m}} \times \mathrm{k}_{\mathrm{b}}$

when $l_{p}$ is a value of admissible (design) traffic flow intensity in the vehicle per hour (veh/h), $l_{z}$ is the basic value of admissible intensity of the traffic flow (veh/h), $k_{k}$ is coefficient of the influence of the traffic-light controlled intersection, $k_{s}$ is width 
coefficient, $k_{m}$ is manoeuvre coefficient and $k_{b}$ is coefficient of very slow-moving vehicles.

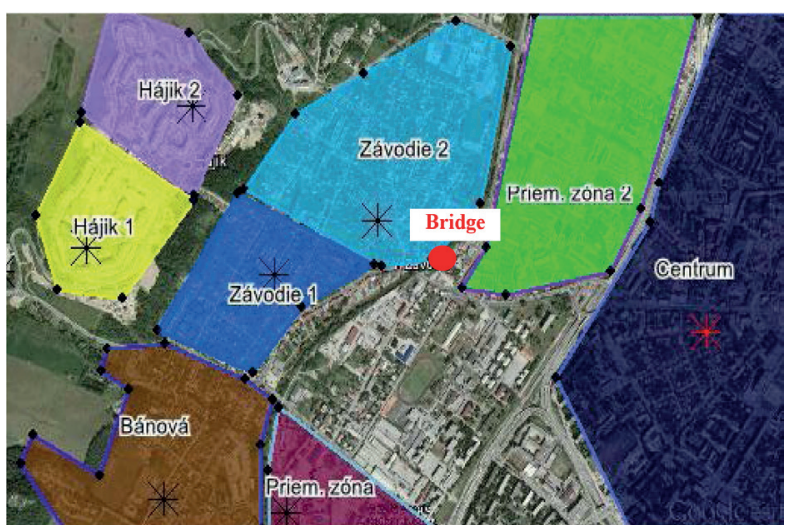

Fig. 4 Defining the zones and districts in the area [authors]

Coefficient values used at the designing of the simulation model:

$1_{\mathrm{z}}-\mathrm{v}=50 \mathrm{~km} / \mathrm{h}$, longitudinal tilt $0-1.5 \%, 5 \%$ of slow vehicles is $l=1250 \mathrm{veh} / \mathrm{h}$,

$\mathrm{k}_{\mathrm{k}}$ - when there is no traffic-light, therefore, the coefficient $k_{k}=1.00$,

$\mathrm{k}_{\mathrm{s}}$ - for one road lane, the width of the lane is $3.5 \mathrm{~m}$, without the adjoining lane $k_{s}=0.75$,

$\mathrm{k}_{\mathrm{m}}$ - for one road lane in given direction we choose $k_{m}=0.96$,

$\mathrm{k}_{\mathrm{b}}$ - at $5 \%$ proportion of slow vehicles, the coefficient of the influence is $k_{b}=0.9$ [3].

When we substitute these values into the equation (1) we get

$l_{p}=1250 \times 0.75 \times 0.96 \times 0.9=810 \mathrm{veh} / \boldsymbol{h}$.

To be able to define the intersection in the traffic hubs, at least three road branches must interlink there. In the model of the road network in the area of interest, there were defined in total 8 intersections out of which one was a roundabout.

\subsection{Defining the transport matrix and scripts}

After the design of the road network model, transport links were defined into so-called traffic matrix. Typically, the input values, which were found or determined according to [11], give information about where the traffic flows begin and where they will direct. A very important part is to create a script of a programme task where traffic network, input data and programme tasks constitute basic elements for elaboration of the functional and adequate virtual model.

\section{Simulation experiments with the traffic model of selected road network}

Within our case study we created three simulation models, namely:

Model 1 = transitivity of the bridge without restrictions - normal state.

Model $2=$ transit restriction over the bridge at the entry and exit from the sector Zavodie.

Model 3 = blocked bridge, detour suggestions and changes in traffic organisation.

All three models incorporated equations focused on the intensity of the traffic flow and density of vehicles on $1 \mathrm{~km}$ section at the maximum speed in the residential area $v=50 \mathrm{~km} / \mathrm{h}$. For each simulation model, calculations were made in three timescales between 07:05 to 08:55 am. Due to limited extent of the article, only the outcomes of the analyses of Model 2 and Model 3 will be presented in more detail.

\subsection{Simulation model 1 - cleared object without restrictions, normal state}

The model is based on the assumption that the road sections considered are with no restriction. The most serious situation in the area usually occurs at about 8:30 (Fig. 5) when most of the roads surpassed the maximum intensity corresponding with the selected level of service for this type of road (approx. $810 \mathrm{veh} / \mathrm{h}$ ).

According to the model, the worst situation occurs on the Zavodska Street in front of the roundabout where the traffic intensity reached the value of approx. $1650 \mathrm{veh} / \mathrm{h}$. We note that all roads from the town districts and surrounding villages join there in the direction to the city centre.

\subsection{Simulation model 2 - blocked bridge}

The simulation model 2 deals with the blocked transit over the bridge which is on the entry and exit of the sector Zavodie and joins the J. Zavodskeho Street and Zavodska Street. By the modification of the model intersections we achieved that in the model, the bridge will be considered as impassable. The other conditions stay the same as in the simulation model 1 . The simulation and the analysis showed that the situation is more complicated comparing to the conditions of the Model 1 (Fig. 6).

The intensity of the traffic in direction to the city centre is significantly higher. For example, the situation on Zitna Street reached twice as many vehicles as envisaged in the calculation. The intensity at $08: 25 \mathrm{am}$ comes to $1650 \mathrm{veh} / \mathrm{h}$ in direction to the centre and to the industrial zone. With very high probability, the predicted situation at that time would cause congestions. As in the case without restrictions (Model 1), even in the case of 


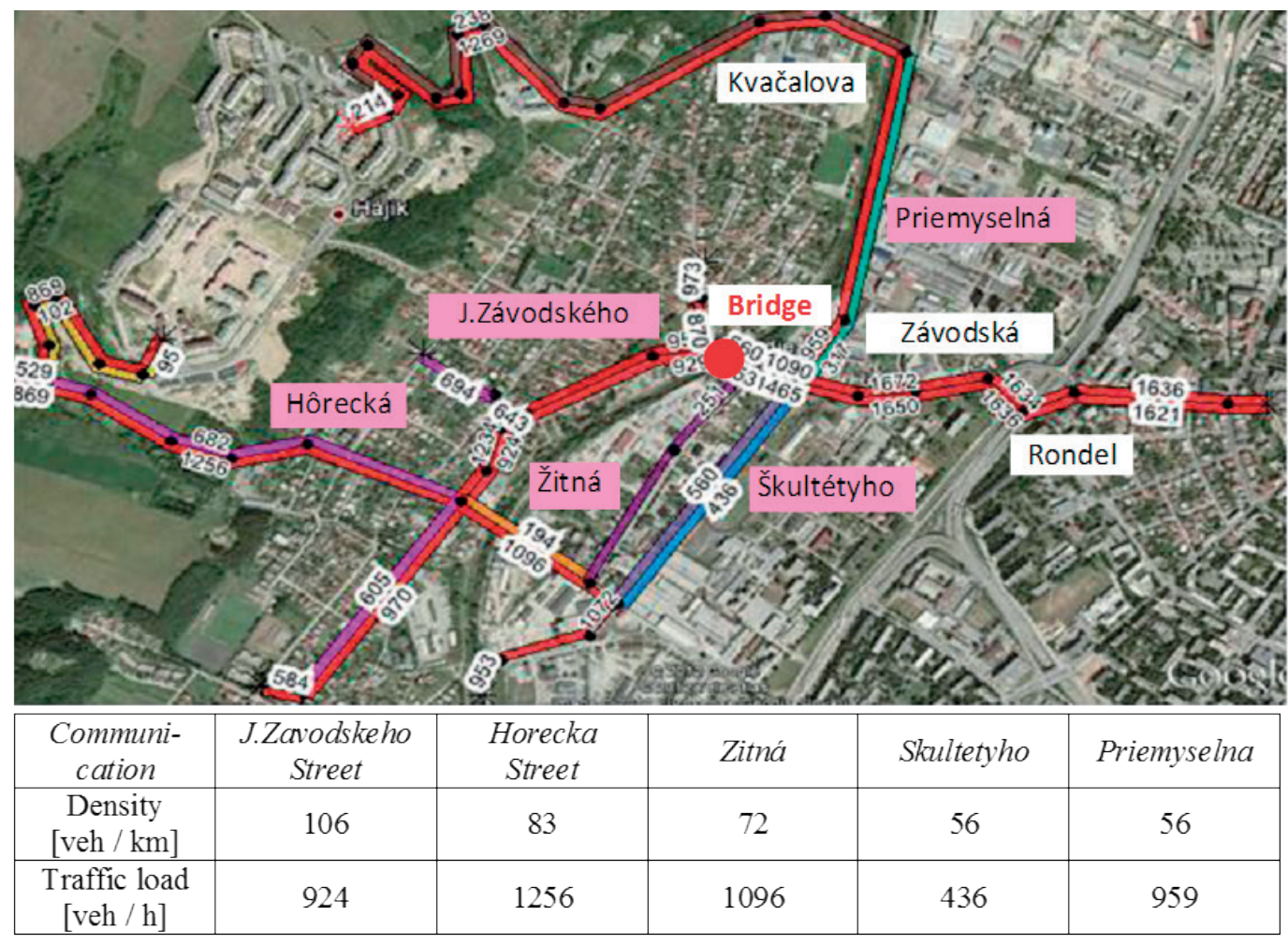
Band Widths
zatazenie
맘 $0=40$
ㅁ $80-30$
ㅁ $80-100$
ㅁ $100-150$
\begin{tabular}{l}
$150-200$ \\
\hline
\end{tabular}
ㅁ $200-250$
ㅁ. $250-300$
ㅁ $300-350$
ㅁ $350-400$
․ $400-450$
ㅁ $450-500$
$500-800$
000.700
- $700-800$
므 $>800$

Fig. 5 Model 1 - Traffic situation at 08:25 [authors]

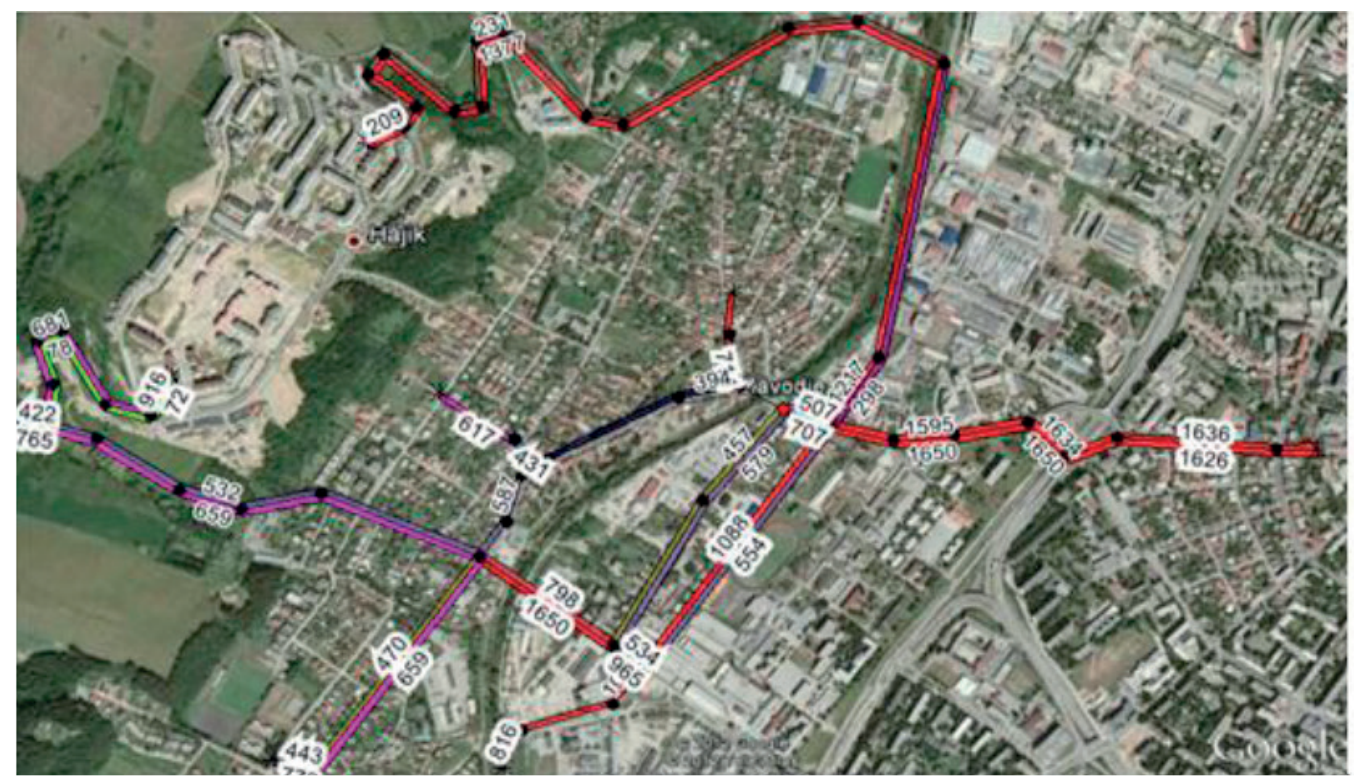

Band Widths

zatazenie

ㅁ 0.40

ㅁ 40.60

ㅁ 60.80

ㅁ 80.100

ㅁ $100 \cdot 150$

$150-200$

ㅁ $200-250$

ㅁ $250 \cdot 300$

ㅁ $300 \cdot 350$

I 350.400

ㅁ. $400-450$

ㅁ 450.500

다. $500-600$

600.700

ㄷ $700-800$

a $>800$

\begin{tabular}{|c|c|c|c|c|c|}
\hline $\begin{array}{c}\text { Communi- } \\
\text { cation }\end{array}$ & $\begin{array}{c}\text { J.Zavodskeho } \\
\text { Street }\end{array}$ & $\begin{array}{c}\text { Horecka } \\
\text { Street }\end{array}$ & Zitná & Skultetyho & Priemyselna \\
\hline $\begin{array}{c}\text { Density } \\
\text { [veh / km }]\end{array}$ & 0 & 132 & 55 & 44 & 46 \\
\hline $\begin{array}{c}\text { Traffic load } \\
\text { [veh /h] }\end{array}$ & 0 & 659 & 1650 & 554 & 1217 \\
\hline
\end{tabular}

Fig. 6 Model 2 - Situation at 08:25 with blocked bridge [authors] 
Model 2, the worst situation is on the roundabout intersection. The worst conditions are on roads which connect the roundabout with Rondel. The traffic intensity is twice as high as the intensity intended for this road. The roads in Banova are below the established intensity, so there are not expected any significant problems in this area. At 8:55 am, the intensity on several main sections is even higher.

To compare the situation in the given sections, Fig. 7 shows certain parameters (density of the flow and traffic load of the road) during selected time sessions.

\section{Situation at Žitná street in time periods}

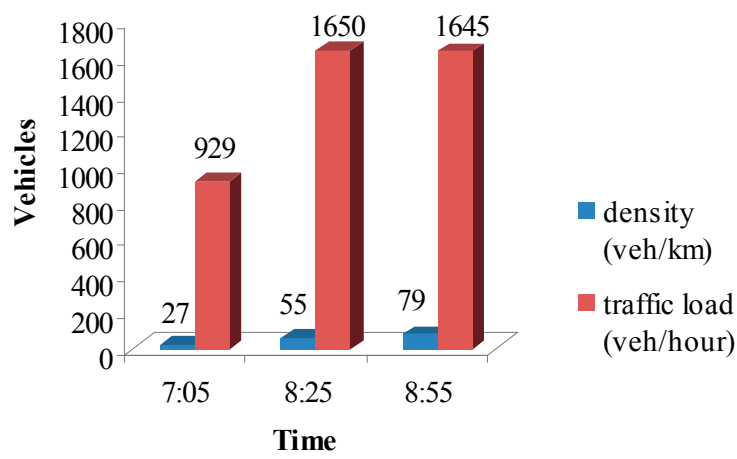

Situation at Škultéty street in time periods

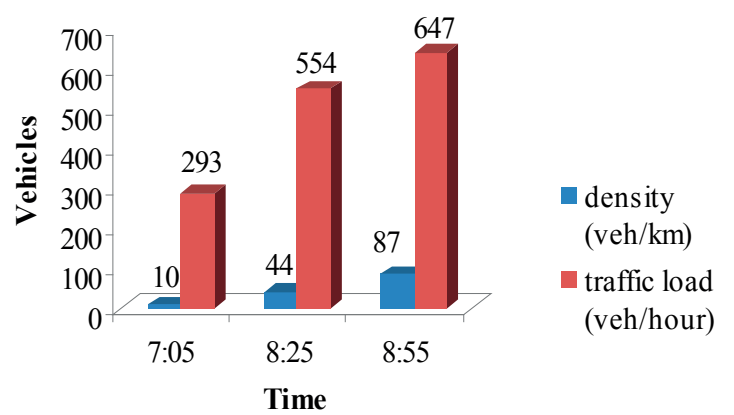

Fig. 7 Model 2 - situation on Zitna and Skultety [authors]

The values of the monitored parameters show that, in this case, the worst situation is on Zitna and Skultetyho Street. The situation is definitely caused by the breakdown of the bridge, with just these two roads being the only possible route to the city centre.

\subsection{Simulation model 3 - blocked object, detour, change of traffic organization}

A prediction resulted from the Model 2 showing how the situation would look like under restricted transit conditions over the bridge. Due to the blockage of the bridge, the traffic flow to the city centre from the direction of Horky and Hajik 1, Banova and Zavodie would pass through the Zitna Street and, consequently, through Skultetyho Street, alternatively through the street Pri Rajcianke. This natural solution would result into significant increase of the traffic load on these roads. It is based on the knowledge of the actual traffic behaviour. Usually, the most suitable solution used for the reduction of the traffic load is a diversion or distribution of the traffic load into other directions. One of the analysed solutions was to divert the traffic from Hajik 1 through Hajik 2 in direction towards Priemyselna to the roundabout (Fig. 8 blue). In the models 1 and 2, this route was not even considered, as it is twice as long and drivers, under normal conditions, often use the shortest routes (Fig. 8 red).

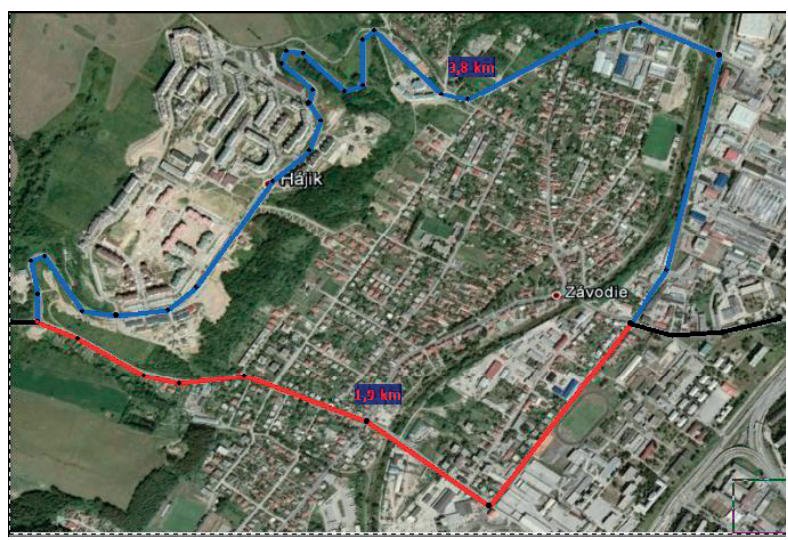

Fig. 8 Detours suggestion and routing of traffic flow [authors]

To avoid reduction of the planned traffic intensity in the area of interest, it was necessary to limit the transitivity of several roads. One of the modifications was a change of traffic organization on the roundabout junction of the Skultety, Priemyselna and Zavodska (Fig. 9).

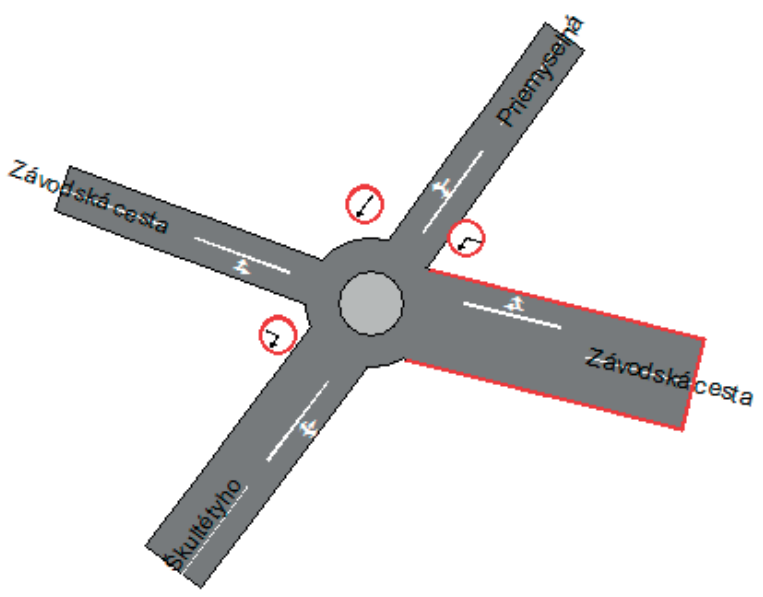

Fig. 9 Turn limitations on roundabout [authors] 

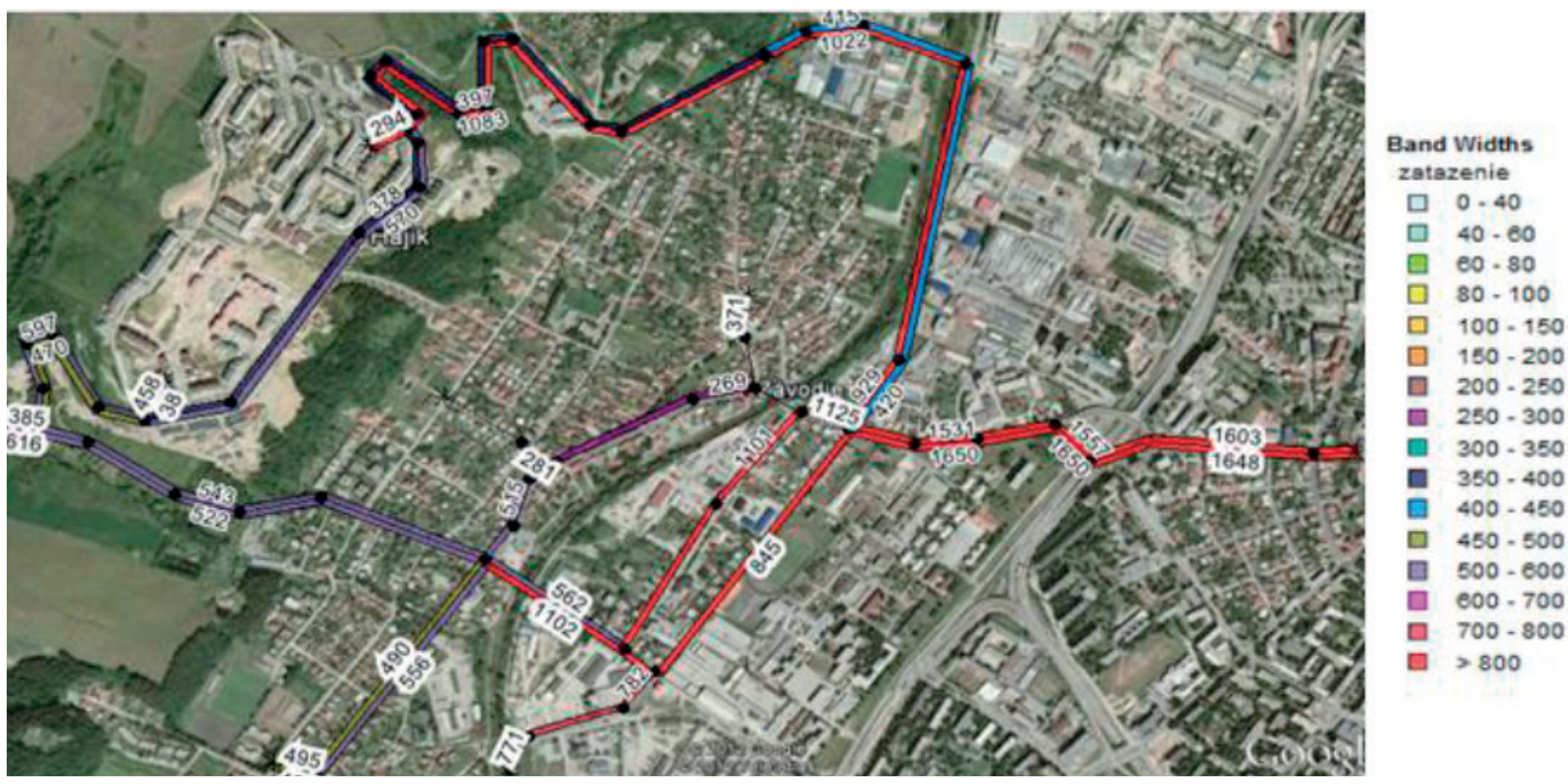

\begin{tabular}{|c|c|c|c|c|}
\hline $\begin{array}{c}\text { Communi- } \\
\text { cation }\end{array}$ & Horecka Street & Zitná & Skultetyho & Priemyselna \\
\hline $\begin{array}{c}\text { Density } \\
\text { [veh / km }]\end{array}$ & 185 & 179 & 118 & 132 \\
\hline $\begin{array}{c}\text { Traffic load } \\
{[\mathrm{veh} / \mathrm{h}]}\end{array}$ & 522 & 1102 & 845 & 929 \\
\hline
\end{tabular}

Fig. 10 Trafic situation at 8:25 using suggested detour [authors]

The proposed limitations and individual redirections in this case would be denoted by temporary vertical road signs, alternatively, during the first days, the traffic could be regulated by the traffic police. In case of implementation of these conditions in the Model 3, the traffic situation is stable. None of the roads is so overloaded to exceed the specified value of the traffic intensity. However, at 8:25 the estimated situation changes significantly.

As shown in Fig. 10, on Zitna Street, the traffic flow increased rapidly and the predicted intensity of vehicles rose to approx. $1100 \mathrm{veh} / \mathrm{h}$. The traffic intensity between roundabout and Rondel is consistently high and, in this respect, it cannot be expected to reduce the traffic flow significantly. A slight increase occurred on Priemyselna, which could have been expected since the traffic from Hajik was redirected there.

\subsection{Comparison of alternatives without (Model 2) and with the detour (Model 3)}

In order to evaluate the impact of the proposed solution (inclusion of detours and change of two-way roads into one-way) it was necessary to compare the parameter values of the traffic flow. The results of the study lead to the assumption that the change in direction of the traffic flows and introduction of the alternative detour route had clearly positive effect on the transport services in the area and on the fluency of the traffic flow.

One of the most important results of the study was to demonstrate the possibilities to reduce the critical level of traffic load on Zitna Street and we can say that the detour and regulation of the direction of traffic flow had clearly positive influence on the traffic in the analysed part of the road network. Completion of the case study should involve experimentally verified characteristics of the traffic flow directly in real traffic. For example, if we implemented the considered blocking of the bridge and also all the regulatory and technical measures into practice and by the consequent survey determined the characteristics of the traffic flow and compared them with the predicted values.

\section{Results summary and discussion}

In case an emergency state with an impact on the transport system arises and it is possible to use simulation tools to verify or optimize the proposed solution, it is necessary to consider:

1. How much time is needed to eliminate the consequences? At situations, the effects of which are possible to be removed within several hours, max. days, it would be sufficient to plan a detour, divert traffic or reduce the transitivity of several roads, only on the ground of subjective assessment and 
familiarity with the location. For longer lasting situation or before a planned reconstruction of the object, it is appropriate to use software in the phase of decision-making. This would enable us to define more variants of solution, experiment with the model and choose the most suitable variant [9].

2. How much time is needed to obtain data and documents to design the most realistic model? To create a traffic network we need maps. The most important are the values of transport links which define so-called transport matrix [12]. These data can be obtained from the traffic survey or certain sources from the field of transport [13]. However, it is necessary to compare the time needed to obtain it with the time dedicated to the problem solution. The more data has been collected, the more accurate and reliable the model will become.

3. Possibilities and availability of a suitable simulation tool. Software is not every suitable to simulate the situation. Therefore, it is appropriate to check the possibilities of its application as well as possibilities of realization and usability of the output format.

4. Staffing the work with the model. In order to consider the obtained result as relevant, it is necessary to have staff who will be able to perform design and analysis of solutions in as short time as possible and with the most precise outputs.

5. Considering stochastic nature of internal - and external variables (such as human factor, weather conditions, traffic intensity, etc.) on transport. In real traffic the state, parameters and dynamics of the traffic flow are influenced by other factors which are not taken into consideration by any simulation tool and any other intelligent traffic management system either [12]. The most important element affecting the overall flow of traffic is human behaviour as an element of the traffic system.

6. Limited influence of random parameters of operating conditions in the road traffic. Current state of meteorological conditions is another of the important factors influencing the traffic. Not always it is possible to consider such factors in the development of simulation model and, therefore, the results of the simulation experiments can be often doubted.

\section{Conclusion}

The risk of unexpected, mostly negative events in the traffic system is closely related to the increased intensity of the traffic as well as to the influence of meteorological, technological and social phenomena. The occurrence of these risks is conditioned by circumstances and phenomena usually of natural or technogenic character. However, the traffic infrastructure can be also influenced or restricted by planned reconstruction or repair of an important object or a section of the traffic infrastructure. The objective of our article was to demonstrate the possibilities of efficient use of software tools to model traffic when assessing the importance of an object of the road infrastructure.

The gist of determination of its criticality lies in the quantification of possible failure impacts on the traffic system functioning. In this case, the bridge structure near the centre of Zilina was selected. Based on the results of the application of simulation models to estimate the traffic load in standard but especially in specific conditions, it has been proven that the simulation methods have important place at the solution of the capacity problems of the traffic.

General solution of the problematic situation (particularly of long-term character) in the road infrastructure can be modified and verified according to the set requirements and restrictive conditions on adequate virtual models of the infrastructure and its important objects. Thus, it is possible to efficiently predict the importance and impact of the disengagement of important objects on transport services in the selected area of the road infrastructure. It is necessary to begin to promote the use of such tools. They streamline the work by fast and efficient suggestions and evaluations of more variants of solution are able to assist in choosing of the most suitable one.

\section{Acknowledgements}

The article was supported by the project APVV-0471-10 „Protection of critical infrastructure in the transport sector“, project „Centre of excellence for systems and services of intelligent transport II“, ITMS 26220120050, co-financed by the European Regional Development Fund and FP7 project „Risk analysis of infrastructure networks in response to extreme weather (RAIN)“.

\section{References}

[1] Act 45/2011 of Coll. on Critical Infrastructure (in Slovak), Bratislava : Slovak National Council.

[2] SIMAK, L., DVORAK, Z., GASPIERIK, L., KAMPOVA, K., REITSPIS, J., SEIDL, M., SVETLIK, J.: Critical Infrastructure Protection in Sector Transport, $1^{\text {st }}$ ed., 180 p., University of Zilina, 2012, ISBN 978-80-554-0625-1.

[3] DVORAK, Z., RAZDIK, J., SOUSEK, R., SVENTEKOVA, E.: Multi-agent System for Decreasing of Risk in Road Transport. Proc. of the $14^{\text {th }}$ Intern. Conference Transport means 2010, October 2010, Kaunas : University of Technology, ISSN 1822-296X. pp. 100103. 


\section{COMMNICOIIIONS}

[4] SVENTEKOVA, E., DVORAK, Z.: Theoretical Frame for Testing Critical Transport Infrastructure Elements. J. of Engineering Management and Competitiveness (JEMC) [electronic source], ISSN 2217-8147, vol. 3, No. 2, 2013, pp. 37-40. Available at: http:// www.tfzr.uns.ac.rs/jemc/files/Vol3No2/V3N22013-01.pdf

[5] VIDRIKOVA, D., DVORAK, Z., KAPLAN, V.: The Current State of Protection of Critical Infrastructure Elements of Road Transport in Conditions of the Slovak Republic, Kaunas University of Technology, 2011.

[6] LEITNER, B., DVORAK, Z., SVENTEKOVA, E.: Traffic Flow Modelling at Restrictive Conditions on Road Infrastructure (in Slovak). ITS 2013 [electronic source] = Intelligent transportation systems 2013: virtual conference: August 26-30, 2013. University of Zilina, 2013, ISBN 978-80-554-0763-0, pp. 104-111.

[7] GOGOLA, M.: Transport Planning in OmniTRANS - Guide for Exercises (in Slovak), PEDAS: University of Zilina, 2008, CD version.

[8] OmniTRANS [online] [cit. 2014-06-02]. Available at: http://www.pbaprague.cz/ download/omnitrans-cz.pdf.

[9] Simulation Studies [on line]. Modelling in Transport: The process of Simulation Study (in Czech). Available at: http://kds.vsb.cz/mkk/ modelovani-10.htm.

[10] STN 636110 - Designing Local Roads (in Slovak).

[11] NOVAK, R.: Analysis and Use of Software Tools to Traffic Conditions Simulation in Specific Crisis Situations (in Slovak), Diploma work, University of Zilina : FSI, 2012, 79 p.

[12] Transport Modelling, Chapter IV. Traffic Modelling on Roads (in Czech), [cit. 2014-01-10] Available at: http://projekt150.ha-vel.cz/ node/94. http://www.ioda.cz/.

[13] RIHA, Z., SOUSEK, R., NEMEC, V.: Transportation and Environment - Economic Research, The $18^{\text {th }}$ World Multi-conference on Systemics, Cybernetics and Informatics, Orlando : Florida, July 2014, ISBN 978-1-941763-05-6. 